\title{
Lessons from Lockdown: Parent Perspectives on Home-learning Mathematics During COVID-19 Lockdown
}

\author{
Lisa Darragh ${ }^{1}\left[\right.$. Nike Franke ${ }^{2}$
}

Received: 9 February 2021 / Accepted: 28 August 2021 / Published online: 26 September 2021

(c) Ministry of Science and Technology, Taiwan 2021

\begin{abstract}
During the COVID-19 pandemic, many parents suddenly had to assume responsibility for their children's learning at home. Research conducted before the pandemic showed that mathematics homework is often unsuccessful or stressful for both parents and children and that tension exists between home and school in the learning of mathematics. Understanding parents' experience of home-learning mathematics during lockdown has implications for positive learning relationships between home and school in the future. During the lockdown, we sent an online survey to New Zealand parents and received 634 responses. We found that parents were generally very engaged in the home learning of mathematics. They reported a range of opinions about the quality of mathematics work and teacher support, and there was a correlation between general stress levels and negative opinions. To further support their child's mathematics learning, many parents turned to online mathematics programs, about which they were very positive. Parents of younger children were more positive about their overall home-learning experiences of mathematics, but the crisis brought to the fore several pre-existing issues. We argue that these findings have implications for mathematics home learning in the future; we suggest that schools listen to parental feedback regarding the quality, level, and quantity of mathematics work. Additionally, schools could consider ways to deliver effective teacher support and to foster parental agency in helping their children with mathematics learning.
\end{abstract}

Keywords Homework $\cdot$ Home-learning mathematics $\cdot$ Pandemic $\cdot$ Parents $\cdot$ Online mathematics

Lisa Darragh

1.darragh@auckland.ac.nz

1 Faculty of Education and Social Work, The University of Auckland, Auckland, New Zealand

2 Liggins Institute, The University of Auckland, Auckland, New Zealand 


\section{Introduction}

On March 25, 2020, Aotearoa New Zealand went into lockdown to prevent the spread of the coronavirus disease, COVID-19. Schools responded quickly; some sent packages of material or loaned a Chromebook or laptop to their students. Teachers emailed their students daily or weekly study plans, and some held regular meetings or lessons online. The government supported these efforts by delivering tens of thousands of laptops as well as hard-packs of study material to households with limited internet (Collins, 2020), and educational TV was implemented to supplement learning content. However, despite this support, parents were suddenly thrust into the position of facilitating their child's learning at home.

During this time, various discourses were circulating in the media. One of these was he waka eke noa-meaning we are all in this together or, more literally, we are all in the same boat. This was primarily a message from leaders to promote public cooperation with the strict lockdown imposed on New Zealanders (e.g., Goff, 2020). Other strong media messages centered around stress-discussing either the general anxiety related to the uncertainty of the situation (MacDonald, 2020) or to the economic impact on the country (New Zealand Herald, 2020) and the financial stress it was likely to put on individual families (Glass, 2020). Such stress may have affected families' ability to help their child's learning at home. Research has found that mathematics homework, in particular, often generates tension between parents and children (Else-Quest et al., 2008; Lange \& Meaney, 2011), which may have further contributed to any stress in the learning environment.

Since parents assumed the teacher's role during the COVID-19 lockdown, we need to understand how they experienced this role. Such an understanding will have future implications, both in terms of the mathematics-learning relationship between parent and child or between parent and school as well as the place of online learning of mathematics. This exploration into parental perspectives of mathematics home learning is likely to resonate internationally due to the pandemic's global nature.

\section{Literature Background}

The sudden requirement for all children to learn mathematics at home was unprecedented. However, we may turn to research into home learning (or homework) of school mathematics to inform what has transpired. There is some debate about whether parental help with homework is beneficial to learning mathematics (Landers, 2013; Roschelle et al., 2016; Shapira-Lishchinsky \& Zavelevsky, 2020). Patall et al. (2008) conducted a meta-analysis of parent involvement in homework and found a negative association with mathematics achievement when contrasted with other curriculum areas, which they hypothesized was due to parents' lack of recent exposure to mathematics learning and conflicting strategies for doing mathematics. Landers (2013) suggested that mathematics is unlike other subjects because of differing levels of parental resources and differing student perceptions; she argued that issues of identity and the valuing of homework 
play roles in the success of homework involvement. Such an argument echoes McMullen and de Abreu (2011) who found that successful homework interactions between mother and child were affected by the identities of both as well as their valuing of different numeracy practices. Certainly, the quality of the parent-child interaction is important; research has found a range in the amount of scaffolding and positive support given by parents (Baranovich et al., 2019; Hyde et al., 2006) as well as the degree to which parents valued "productive struggle" during homework (Vazquez et al., 2020, p. 1).

Emotional aspects may also affect successful interactions during homework. For example, parents' emotional arousal affected their willingness to help their children with mathematics homework (Bartley \& Ingram, 2018). Sometimes mathematics homework can be traumatic; Lange and Meaney (2011) argued that when schools require children to engage in procedural mathematics, it positions children as passive learners and adds to homework trauma by affecting the parent-child relationship. By contrast, if homework is child-led but designed to involve the parent, it can reduce tension and build children's self-efficacy in mathematics (Williams et al., 2017). Both positive interest and tension were found to be the most frequent emotions displayed in a study of 11-year-olds doing mathematics work with their mother (Else-Quest et al., 2008); positive emotions depended on warmth and collaborative support and the child's trust of their mother's ability to do the homework.

Parental mathematics ability is argued to affect the quality of the homework interaction (Hyde et al., 2006). For example, for higher levels of schooling, parents may be less skilled (Landers, 2013) or less confident (Jay et al., 2018) about helping. One study found that parents who were mathematicians (i.e., holding $\mathrm{PhDs}$ in pure mathematics) were less involved in their children's homework than other parents, although the mathematicians did provide a rich mathematical home environment for their children including playing board and strategy games (Drešar \& Lipovec, 2017). In some studies of parents who attended workshops to learn their child's mathematics, parents—despite not having mastered the material—nevertheless saw themselves as resources for their child's learning; they positioned their child as the teacher and worked in parallel to collaborate on homework in a positive way (Ginsberg, 2006; Knapp et al., 2017).

A barrier to quality homework interactions appears to be curricular and pedagogical changes in mathematics education (Remillard \& Jackson, 2006). Parents are less able to draw on their past mathematics educational experience because what counts as mathematics and what are appropriate learning strategies have changed (Crafter, 2012; de Abreu \& Cline, 2005; McMullen \& de Abreu, 2011; Patall et al., 2008; Wadham et al., 2020). It seems thatreform mathematics may act to disempower parents as players in their children's education (Remillard \& Jackson, 2006). A consequence of such disempowerment may be a deficit view of parents by the school (McGee \& Spencer, 2015; Schnee \& Bose, 2010). For example, in one study of parent-school partnerships for mathematics learning in an ethnically diverse school, tensions were found to exist in (a) the differing computational strategies used by parents and the school and (b) the lack of communication from school to home about new pedagogies (Wadham et al., 2020). In such examples, we see mathematics homework as potentially affecting home-school relationships. 
There is a body of research that looks at parental involvement in school mathematics in a broader sense. Sheldon et al. (2010) analyzed the partnership activities of 39 schools and found that the home environment and degree of family involvement is associated with mathematics performance. Some challenges for schools in developing positive partnerships are language difference (de Abreu \& Cline, 2005; Sheldon \& Epstein, 2005), finding ways to give parents a voice (Wilder, 2017), and providing parent-centered approaches to fostering partnerships in mathematics learning (Jay et al., 2018; Remillard \& Jackson, 2006). Schnee and Bose (2010) argued that what is perceived to be a lack of involvement may actually be a demonstration of parental agency in their choice to opt out of helping with homework. However, it is the nature of parents' interactions with their children at home that has a stronger predictive power than the degree of parental involvement in school mathematics (Wilder, 2017); and the quality of home-school mathematics partnerships is more important than quantity (Sheldon et al., 2010).

Comparatively absent in the mathematics education literature on home learning is the use of online programs for learning mathematics at the primary and secondary school levels. Mobile technologies mean that educational platforms may be accessed from home as well as the classroom, yet research into digital technologies in mathematics learning tends to focus on the school context (Bano et al., 2018). Two studies examined the effects of online mathematics homework on achievement and reported better results when compared to traditional homework (Mendicino et al., 2009; Roschelle et al., 2016); in each case, achievement was higher with online homework, but neither examined parental involvement.

In New Zealand, many schools use online mathematics instructional programs (Wright \& Peters, 2017), partly to engage with learning at home (Darragh \& Franke, 2021). These programs are subscription-based and typically have a financial cost borne by either the school or the parent. There is some research into these programs, with the majority focusing on either the program itself (Robin \& Kwak, 2018) or as part of a wider survey of the educational landscape (Borba et al., 2016). Much research includes such programs as part of a broader investigation of digital technologies used in schools (Attard \& Holmes, 2020; Nicholas \& Fletcher, 2017). One example of research into subscription-based online programs in the home setting is the Screen Stories Project (Nansen et al., 2012), which aimed to understand children and their families' experiences of digital technology in terms of relationships and social inclusion. In that project, Mathletics emerged as a significant program that was used regularly for homework activities as well as for fun. Parents were supportive of the application because of the perceived affordance of digital access, education, and literacy.

To summarize, parental involvement in learning mathematics at home is seen as beneficial in general, but there are important caveats. Help with homework may be negative and emotionally traumatic; parents may not have the ability or confidence to help, or they may feel disempowered by curriculum change. Yet the reverse may be the case depending on the mathematics identities of parent and child, their valuing of the homework, and the approach that is taken. In any case, it may be challenging for schools to develop positive partnerships with parents regarding mathematics learning. Lacking in the literature is research about online mathematics learning 
at home, and yet online learning platforms may very well enjoy an enhanced salience in their position as a significant pandemic pedagogy (Williamson et al., 2020). Lacking also in the literature of parental involvement in mathematics homework is research regarding parental stress affecting successful homework interactions. Finally, it appears that home learning of mathematics is particularly difficult in comparison to other subjects. Assuming that the intensity of the lockdown experience of home-learning mathematics would glean valuable information about parents' perspectives, we posed the following research questions:

- How did parents experience their child's mathematics learning during the COVID-19 lockdown?

- Did private online instructional programs play a role in mathematics learning during the lockdown?

- Did family circumstance (i.e., financial or emotional stress, family structure, age of children, socioeconomic status, internet access) affect mathematics learning experiences at home during the lockdown?

\section{Methods}

To answer these research questions, we employed a mixed-methods exploratory design (Cresswell, 2014) that used a survey collecting both quantitative and qualitative data and a standardized measure of depression, anxiety, and stress.

\section{The Instrument and Data Collection Methods}

We developed an online survey containing four sections: demographic information, questions about the children under the respondents' care, questions about home-learning mathematics, and the Depression Anxiety Stress Scales for adults (DASS-21; Lovibond \& Lovibond, 1995). The survey questions began with basic demographic information about the parent respondents. Questions about the children under care included their year level, gender, internet access, and enjoyment of mathematics. Questions about home learning included the amount of time an adult was available to help, a rating of how important home learning was, where learning material was sourced (e.g., educational TV, provided by the school, a caregiver, or Ministry of Education), whether and from where parents sourced online educational resources for mathematics learning, and how these were selected and paid for. Three open-ended questions asked parents to comment on the mathematics work provided by their child/children's school, their opinion of subscription-based, online mathematics learning programs (if subscribed), and an overall comment about the challenges or positive aspects experienced during home learning of mathematics.

In line with the discourse circulating in the media, we assumed that the lockdown situation would be stressful, both emotionally and financially; and we suspected that this stress would affect parents' experiences of home-learning mathematics. Participants were asked to rate their level of financial pressure during the pandemic and to 
complete a 21-item questionnaire on their level of depression, anxiety, and stress. Some sample items from the DASS-21 are as follows: "I felt that I had nothing to look forward to"; "I felt scared without any good reason"; and "I found it difficult to relax" (Lovibond \& Lovibond, 1995). Items are scored on a 4-point scale ranging from $0=$ did not apply to me at all to $3=$ applied to me very much or most of the time. The scales had good internal consistency as well as convergent and discriminant validity in previous studies (Henry \& Crawford, 2005). In the current study, internal consistency was acceptable to very good, with $\alpha=0.71$ for anxiety, $\alpha=0.89$ for stress, and $\alpha=0.87$ for depression.

After piloting, we distributed the survey via Facebook ${ }^{\odot}$, primarily targeting community pages to gain a wide geographical spread. At the start of the survey, parents had been in lockdown for four weeks. We received 634 responses over the following three-week period and stopped the survey when it was announced that the lockdown was being eased and children were to return to school.

\section{Participants}

There were 634 respondents who were 16 years or older and cared for one or more children during the COVID-19 lockdown. Table 1 provides demographic details of the parental respondents. The total number of children in the sample was 1,428; of that amount, 111 were either too young or too old to attend school and 57 had missing data. The remaining 1,260 children were in these levels: 723 in primary, 231 in intermediate, and 306 in secondary grades. In the remaining sample there were 658 boys, 593 girls, 1 gender-diverse, and missing gender data for 8 children..

The sample was skewed toward Pākehā (New Zealand Europeans), mothers, those who spoke English, those with a university or postgraduate degree, and those with reasonably high family income. The majority of respondents were locked down with two adults and two to three children and had unlimited internet data in the home. This is not representative of the New Zealand population (Statistics New Zealand, 2020); for example, those identifying as Pākehā were around $80 \%$ as opposed to $70 \%$ nationwide. Conversely, Māori, Pacific, and Asian participation was lower than the nationwide population. The mean household income of $\$ 102,613$ and median household income of $\$ 90,636$ suggests that the sample is more affluent than typical; the education level of the sample is greater than typical of New Zealanders. Most notable is the gender disparity, with only 18 fathers participating in comparison to 596 mothers.

\section{Data Analysis}

In order to gain a general sense of the home-learning mathematics experiences, responses to each of the three open-ended questions were deductively coded according to whether the experience (i.e., school mathematics activities, online subscription programs, or home-learning mathematics in general) was positive, negative, mixed, or neutral. A positive code was given to any positive comment, from the very mild (e.g., "It was fine") to those that were very positive (e.g., "It has been fun 
Table 1 Demographic characteristics of the sample $(N=634)$

\begin{tabular}{|c|c|c|c|}
\hline Variable & & $n$ & $\%$ \\
\hline \multirow[t]{3}{*}{ Caregiver type } & Mother & 596 & 94.0 \\
\hline & Father & 18 & 2.8 \\
\hline & Other & 13 & 2.1 \\
\hline \multirow[t]{5}{*}{ Ethnicity } & NZ European/Pākehā & 504 & 79.5 \\
\hline & Māori & 53 & 8.4 \\
\hline & Pacific Island & 11 & 1.7 \\
\hline & Asian & 25 & 3.9 \\
\hline & Other & 40 & 6.3 \\
\hline \multirow[t]{2}{*}{ Main language } & English & 614 & 96.8 \\
\hline & Other & 18 & 2.9 \\
\hline \multirow[t]{4}{*}{ Highest qualification } & Primary/secondary school & 62 & 9.8 \\
\hline & Polytech diploma & 116 & 18.3 \\
\hline & Undergraduate degree & 229 & 36.1 \\
\hline & Postgraduate degree & 226 & 35.6 \\
\hline \multirow[t]{4}{*}{ Annual family income NZ\$ } & $<75,000$ & 103 & 16.2 \\
\hline & $75,000-100,000$ & 121 & 19.1 \\
\hline & $>100,000$ & 322 & 50.8 \\
\hline & Do not know/prefer not to say & 83 & 13.1 \\
\hline \multirow[t]{4}{*}{ Total adults in home during lockdown } & 1 & 40 & 6.3 \\
\hline & 2 & 506 & 79.8 \\
\hline & 3 & 52 & 8.2 \\
\hline & 4 or more & 34 & 5.4 \\
\hline \multirow[t]{5}{*}{ Total children in home during lockdown } & 1 & 104 & 16.4 \\
\hline & 2 & 329 & 51.9 \\
\hline & 3 & 154 & 24.3 \\
\hline & 4 & 36 & 5.7 \\
\hline & 5 or more & 11 & 1.7 \\
\hline \multirow[t]{3}{*}{ Access to internet data } & Unlimited & 548 & 86.4 \\
\hline & Enough for needs & 67 & 10.6 \\
\hline & Not enough for needs & 17 & 2.7 \\
\hline \multirow[t]{7}{*}{ Work situation during lockdown } & Work outside the home (essential services) & 58 & 9.1 \\
\hline & Adapt to online work from home & 240 & 37.9 \\
\hline & Always work from home & 63 & 9.9 \\
\hline & Could not work from home & 55 & 8.7 \\
\hline & Do not have a paid job & 89 & 14.0 \\
\hline & Other & 54 & 9.6 \\
\hline & Missing & 75 & 11.8 \\
\hline
\end{tabular}

for all of us"; "My kids have thrived with being able to work at their own pace and level without being limited and held back by the slow pace and endless repetition of school based maths"). Similarly, a negative code covered mild responses (e.g., "Not 
overly exciting") to those more extreme (e.g., "It was pure hell"). A mixed code was given to any response that contained both positive and negative comments. Neutral was applied to responses that did not contain an evaluative aspect (e.g., "Didn't look at it"; "Different for each school"); comments that listed content without evaluation were coded in this category (e.g., "Worksheets"). The two authors worked with a research assistant to code the first 250 responses independently and then compared our results in order to agree upon specific coding guidelines. We then divided the remaining responses to two coders and gained interrater reliabilities of $93 \%, 98 \%$, and $91 \%$ for the respective questions. Finally, we met to reach agreement on all differently coded responses.

To explore differences in experience depending on the age of the children, we formed the data into five groups-years 1-3 (junior primary), years 4-6 (senior primary), years 7-8 (intermediate), years 9-10 (junior secondary), and years 11-13 (senior secondary) — to reflect responses by parents with children at these differing stages of schooling. If parents had more than one child, their response was often included in more than one group. We then compared the different stances to homelearning mathematics experiences by group. In many cases, we were able to reallocate a mixed response to either positive or negative, for example:

I hated it with my older child as he wouldn't accept help and wanted me to sit by him the entire time for confidence. Younger child was relatively easy as her y1 work was at a level where she felt confident to do it alone.

This statement was originally coded as mixed; following analysis, it was reallocated positive for the years 1-3 group and negative for the years 4-6 group.

All statistical analyses were done using SPSS version 26. Analyses included descriptive statistics to describe the sample and a series of independent $t$-tests and Chi-square tests to examine associations between family circumstances and parents' solely negative or positive opinion on the overall experience of mathematics learning at home. An additional round of coding with the open responses identified the different positive or negative mathematics home-learning experiences, as per the main research question. For this analysis, mixed responses were combined with the positive and negative responses, which were then coded in an inductive manner (Braun \& Clarke, 2012). Two coders discussed the results of this process and subsequently collapsed some codes to form broader categories.

\section{Findings}

The findings are presented in five sections. First, we outline findings about the parents' engagement in home learning in mathematics, followed by their perspectives of the mathematics work and support provided by the school. We continue with findings about their access to and opinions of online mathematics-learning resources including responses to the second open-ended question asked of those who subscribed to online mathematics instructional programs. The next section contains their responses to the third open-ended question related to the overall experience of 


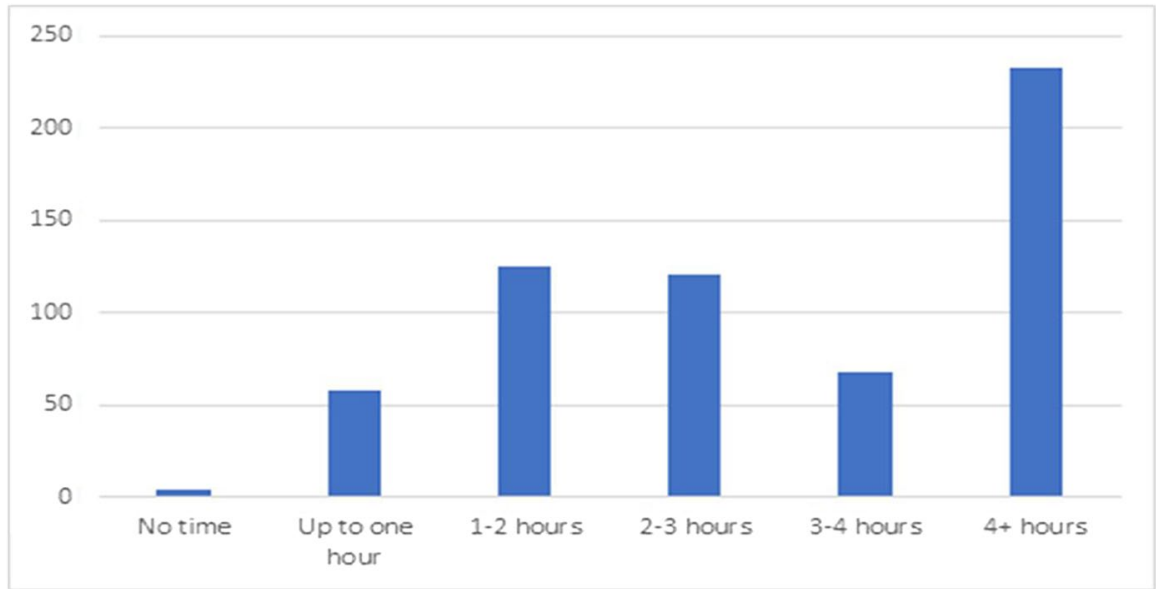

Fig. 1 Parents' time available to help with learning each day during lockdown $(N=634)$

Table 2 Sources of learning for general and mathematics home learning

\begin{tabular}{lll}
\hline Source of learning & General $(n=596) n(\%)$ & $\begin{array}{l}\text { Mathematics } \\
(n=590) n \\
(\%)\end{array}$ \\
\hline Educational TV & $115(19.3)$ & $49(8.3)$ \\
Work provided by school & $570(95.6)$ & $544(92.2)$ \\
Work provided by parent & $292(49.0)$ & $253(42.9)$ \\
Material provided by Ministry of Education & $44(7.4)$ & $35(5.9)$ \\
Other (YouTube $^{\odot}$, play learning, reading books) & $87(14.6)$ & $90(15.3)$ \\
\hline
\end{tabular}

home-learning mathematics during lockdown. The last section presents the results of the DASS questionnaire.

\section{Engagement in Home Learning}

Parents in our sample appeared to be very engaged in home learning. When asked to rate the importance of education during lockdown on a scale of 0 to 10 , the vast majority reported it as important, with a mean score of $7.54(S D=2.21)$ and 10 being the most reported rating $(155 ; 24 \%)$. Correspondingly, they were quite available to help their child with their learning during this time, as shown in Fig. 1.

Parents were asked which types of resources their child engaged with for home learning. As shown in Table 2, most respondents indicated that they used the work provided by their school, but many parents provided work for their child themselves. This may reflect the high average amount of time they had available to help their child, the value they placed on education, or their ability to locate resources. Although work provided by the school was the majority category, it is interesting to 
note the implication that almost $8 \%$ of schools either did not provide mathematics work or this work was not used (Table 3).

\section{Mathematics Work Provided by the School}

This section reports on the responses to the first open-ended question that asked about parents' perspectives of the mathematics work provided by the school (see Table 3).

\section{Positive Responses}

The largest positive response category related to the quality of the work (148), including the nature of the activities (74) and having an appropriate level of challenge (86): "A good mix of things he knew and more challenging things." Many comments were focused on fun: "My year 4 son had a mystery to solve for each week and each day had to solve maths problems to find the clues. He is loving it." Quantity of work (21) was also important to parents, particularly work that their child was able to complete independently (16). Parents had positive comments about the support they received, particularly teacher support in the form of Zoom ${ }^{\odot}$ meetings or videos (37); these were very positive: "Great for my y10, teacher included awesome videos explaining concepts etc." Ten parents mentioned clarity of explanations, and a further nine praised teachers for being well organized and for their level of planning. Finally, some parents-without having seen the subsequent questions about online learning - made positive comments about these platforms (40): "My 6 year old does half an hour of Mathletics and that is perfect."

\section{Negative Responses}

Mirroring the positive comments, the majority of negative comments (136) related to the quality of the assigned work; for example, it was considered the wrong level, confusing, or boring/pointless and repetitive: "A waste of time. Just worksheets with no real learning going on. Random." Additionally, 40 parents thought that the quantity of mathematics work was either too little or too great. Some had concerns with the online nature of the learning (38): "It was only Maths Whizz, which I believe showed no thought from the school or teacher, and no constructive teaching." A few relayed internet or device access issues, but more of these responses were about disliking online apps or internet-based learning. A large number (79) were unhappy with the lack of teacher support:

Really hard! I tried to help with this subject but the info given online ie videos by teacher were absolutely no help at all. We have given up on it which is very frustrating as I don't want him to get behind in his work. All other classes are working well online but not maths.

Relatedly, some commented that the work required a lot of parent help (24). Other parents (18) found it difficult to support their child's learning due to the differences 


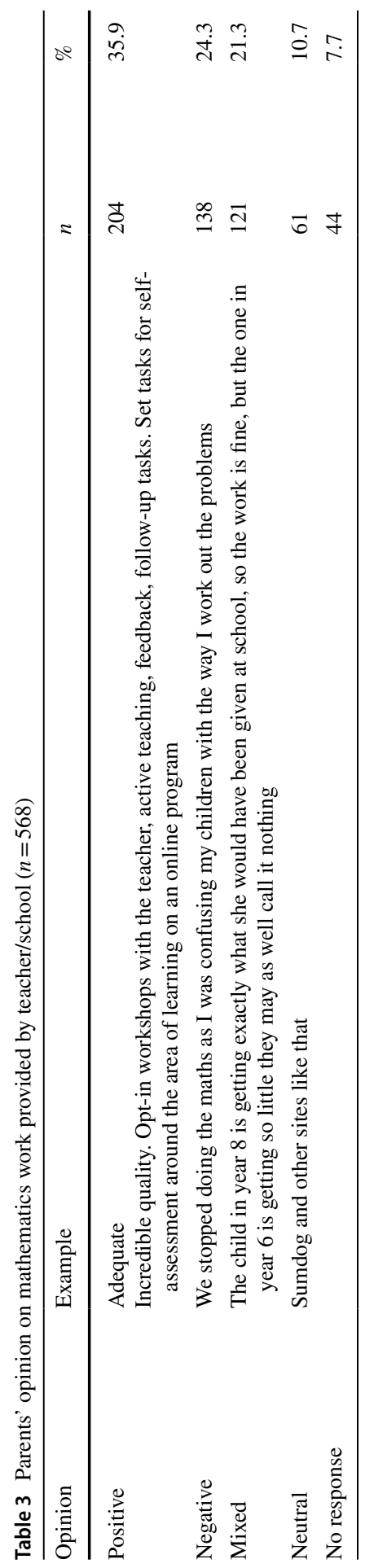


in modern ways of doing maths. Finally, some parents (11) expressed how their dissatisfaction with the provided work led them to find their own resources.

To summarize, parents expressed extremely diverse opinions about the mathematics learning provided by schools. Comments centered on quality and quantity of work, teacher support, and online learning. We noted that 55 responses were coded mixed due to being positive for one child and negative for another, indicating that parents were discerning between differing experiences; they were most critical when assigned work was not relevant to the child or teacher support was not given. However, opinions regarding the learning provided by the school showed no real differences depending on the level of the child. We noted that parents $(n=204)$ who were positive about the work provided by their child's school were significantly less likely to look for additional online mathematics educational resources than parents who expressed negative, mixed, or neutral opinions $\left(\chi^{2}(3)=10.87, p=0.012\right)$.

\section{Accessing Other Online Resources for Learning Mathematics}

Although the sample had a high degree of access to the internet overall, there were certainly some families with less access, which raises equity concerns. We looked at the relationship between annual family income and internet access using Spearman's rank order correlation coefficient. There was a weak but significant positive correlation between the two variables, $r_{\mathrm{s}}=0.122, p<0.05$, with higher levels of family income associated with higher levels of internet access.

In addition to the resources provided by the school, 271 parents (43\%) looked online for additional mathematics educational resources (Table 2). A large number of sites were sourced by parents; in total, 82 different online resources were mentioned with the most common being subscription-based programs. In 408 households, families subscribed to one or more online mathematics instructional programs; clearly, some of these were already subscribed to before the lockdown began. In more cases $(194 ; 48 \%)$, they were paid for by the school, but $111(27 \%)$ paid for it themselves, and 88 (22\%) utilized a free version or did a free trial. A Chi-square test indicated a significant association between income and paying for online programs $\left(\chi^{2}(1)=6.83, p=0.033\right)$, with highest income parents making more use of paid programs than the two lower income groups (Table 4).

There was a huge variety of programs subscribed to by families and schools, a total of 31 different programs. Those with more than 50 mentions included the following: Mathletics (157), Prodigy (127), Study Ladder (117), Education Perfect (93), Maths Buddy (57), and Khan Academy (50). Opinions of these programs were much more positive than negative (Table 5).

Table 4 Cross-tabulation of free or paid online mathematics program by family income group $(n=342)$

\begin{tabular}{lll}
\hline Annual family income & Free for family $(n) \%$ & Paid by family $(n) \%$ \\
\hline$<$ NZ\$ 75,000 & $40(78.4)$ & $11(21.6)$ \\
NZ\$ 75,000-100,000 & $57(81.5)$ & $13(18.6)$ \\
$>$ NZ\$ 100,000 & $148(67.0)$ & $73(33.0)$ \\
\hline
\end{tabular}




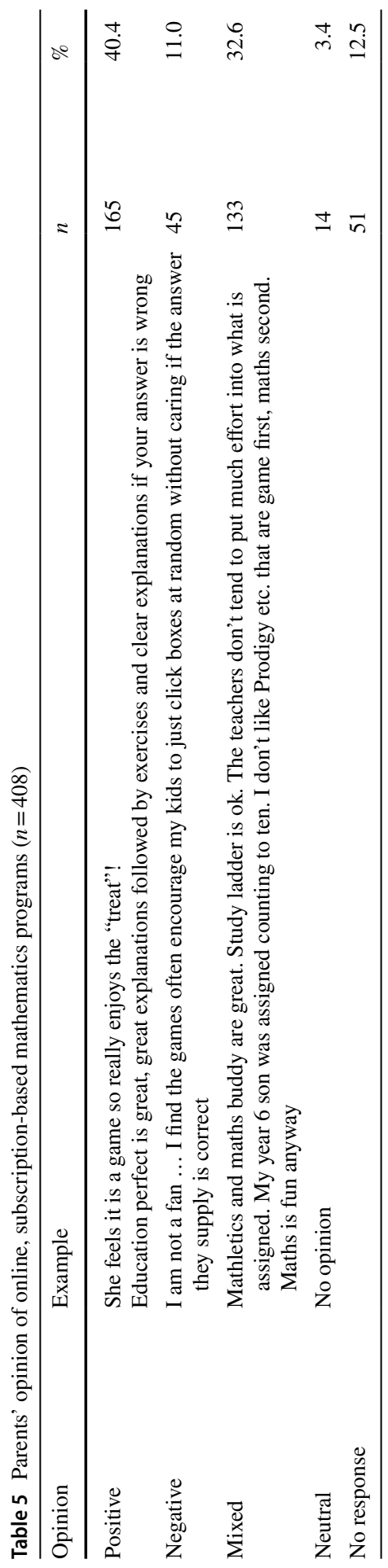


Online subscription programs for mathematics were seen by most parents as fun and engaging (110), but parents also mentioned that they were level-appropriate (29), provided good tutorials (24) and feedback (13), and allowed students to revise independently (13). In short, the aspects parents liked about the online games were those that took up the shortfall in the work provided by teachers and schools. However, some parents (56) noted the lack of educational value in programs that they considered to be only of supplementary value and not a replacement for teaching. A number (34) were concerned with gamification, screen time, and addiction.

\section{Overall Experiences of Home-Learning Mathematics During Lockdown}

The overall lockdown experience involved more aspects than just the school-provided and online work. In the final open-ended question, which asked about the overall experience of home-learning mathematics, parents demonstrated very mixed opinions (Table 6). Several other aspects emerged as key explanatory factors for the success of the experience.

\section{Positive Responses}

Parents' responses to the overall experience of home-learning mathematics during lockdown reiterated comments about teacher support (34) and use of online learning platforms (52); yet parents expressed several additional positives about the lockdown experience. For example, a large number of parents (94) found lockdown positive for their child's learning of mathematics.

On a positive note it has been awesome to see my kids a lot happier about learning by being at home and having support! Teachers seem so stressed that school has turned into such a negative place. To be honest my kids have never really had a teacher actually teach them maths for a long time. They get chucked in front of these programmes at school and either sink or swim. My kids sank a long time ago. I teach them the basics they will actually need for life!

Such responses, while coded as positive experiences of home learning, were harsh indictments of regular school. For some parents (49), the lockdown provided an opportunity to learn about their child and mathematics: "I think the lockdown has been a godsend for us. It has showed me how much my child struggles in school and that because she is quiet and reserved often gets overlooked for help." Such comments indicate that parents felt the teacher did not sufficiently know the child's mathematics needs and that lockdown was an opportunity for the parent to teach their child more adequately themselves.

There were 51 parents who spoke positively about lockdown mathematics, often referencing parent-directed activities. Lockdown was an opportunity to explore real-life mathematics, such as budgeting for travel, house design, counting money, measuring rainfall, and doing building activities. At least 12 mentioned doing mathematics through baking. Others (15) saw the mathematics in playing games, doing 


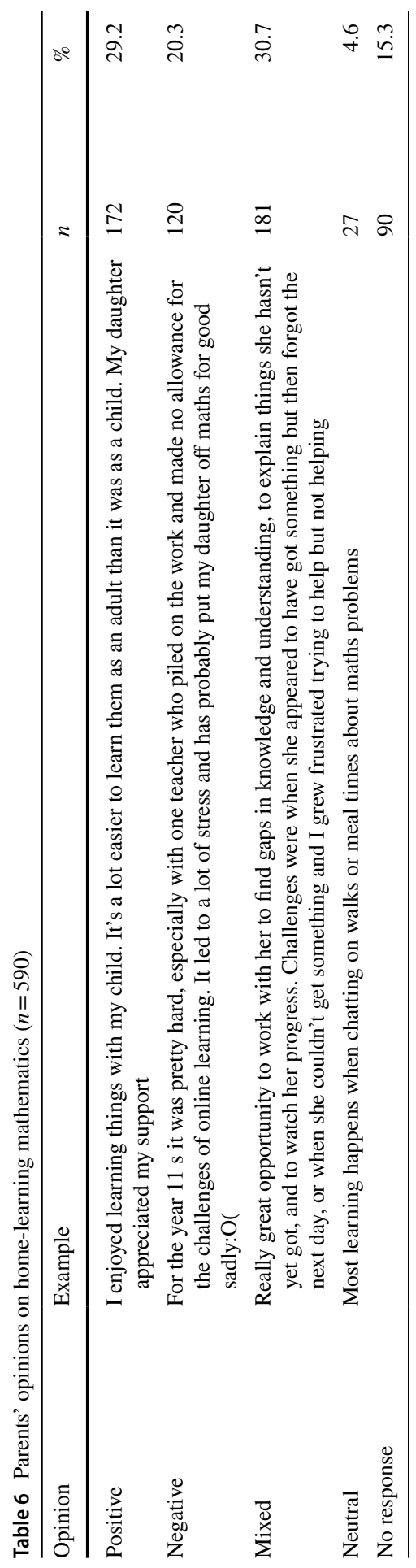


jigsaws, and logic puzzles. A number of parents (20) helped their child to consolidate basic facts such as times-tables or taught their child to tell time. A few incorporated mathematics into their daily walks, looking at letter-box numbers, or doing statistics withteddy-bear sightings in windows (during lockdown, many families displayed teddy-bears in order to connect with the community). By contrast, for some families (39), it was their child's positive mathematics identity that contributed to the success of home learning: "Great. She loves maths, kept asking for more!" Overall, children's mathematics enjoyment was rated fairly high by parents, with a mean rating of 6.43 and a mode of 7 (on a scale of 1-10). Another child-related reason for a successful lockdown experience was being an independent learner (33).

\section{Negative Responses}

Some general comments about the experience of home-learning mathematics mirrored those previously stated: lack of teacher support (54), inappropriate work assigned (82), having to source their own material (20), the challenge of maths being "different in my day" (37), and negative aspects of online learning (28). Other negative aspects discussed related to either the child's or the parent's situation. Although most children were described by respondents as enjoying mathematics, sometimes during lockdown, children were reluctant or disengaged from their work (71). Parents reported a negative mathematics identity in 23 children, 12 had special educational needs, and 30 suffered stress or anxiety during the lockdown.

The whole schooling experience during lockdown was challenging. This surprised me as I thought it would be similar to normal but really just highlighted the disadvantages we face everyday due to my child's learning differences. We are alone.

In other cases, it was difficulties faced by parents that were mentioned. Some (43) said they were unavailable to help due to having to work; this seemed a relatively small number given the number who were essential workers or otherwise working full time. Others (24) found the interactions with their child and/or the situation of home learning to be stressful. A few (20) mentioned difficulties with having to take the teacher role when they were not a teacher, and just five mentioned their own negative mathematics identity. Only when asked about the overall home learning experience did differences emerge in the different year levels.

Unlike the other open-ended responses, the results reported in Table 7 indicate that the parents of years 1-3 children had a notably more positive overall experience than the parents of years 11-13 children and that negative experiences increased consistently with year-level group. We did not find any differences in the nature of these positive or negative experiences; however, there is some indication that parents of younger children felt more agency or ability to engage with home learning in mathematics as evident in their descriptions of activities of their own devising.

Taken altogether, these responses run contrary to research that ascribes success (or lack thereof) in mathematics homework to attributes of parents. Much greater numbers of parents saw the school as responsible for the success or failure of home-learning mathematics; and in cases where the school did not come 
Table 7 Opinion of overall aspects about home-learning mathematics by child's year level

\begin{tabular}{llllll}
\hline Year level & Positive $n(\%)$ & Negative $n(\%)$ & Mixed $n(\%)$ & Neutral $n(\%)$ & Total \\
\hline $1-3$ & $84(40.58)$ & $48(23.19)$ & $65(31.40)$ & $10(4.83)$ & 207 \\
$4-6$ & $96(33.57)$ & $88(30.77)$ & $90(31.47)$ & $12(4.20)$ & 286 \\
$7-8$ & $68(37.78)$ & $57(31.67)$ & $49(27.22)$ & $6(3.33)$ & 180 \\
$9-10$ & $45(34.09)$ & $37(34.09)$ & $40(30.30)$ & $10(7.58)$ & 132 \\
$11-13$ & $25(28.74)$ & $34(39.08)$ & $19(21.84)$ & $9(10.34)$ & 87 \\
Total & $318(35.65)$ & $264(29.60)$ & $263(29.48)$ & $47(5.27)$ & 892 \\
\hline
\end{tabular}

through, there was evidence of potentially damaged relationships: "We felt really let down by the lack of effort from the school." In some comments, we could see that this damage may extend beyond the lockdown period: "The school was awful. No maths worksheets.... We will look to move him post covid as other people's experience was better." Clearly, parents were comparing their experience to that of other schools; in some cases, the schools did not fare well.

\section{Stress During Lockdown}

In this section, we explore the relationship between a positive or negative attitude and parental aspects (i.e., depression, anxiety, stress). Over a third of the sample $(243 ; 38 \%)$ indicated that they experienced very little financial pressure during lockdown, just under a third $(180 ; 28 \%)$ had typical levels, and a fifth (123; $19 \%$ ) experienced medium-high or high levels of financial pressure. As shown in Table 8 , the vast majority of the sample had low or normal levels of depression, anxiety, and stress according to the DASS-21 guidelines.

Comparing 164 parents who expressed solely positive opinions of home-learning mathematics to the 122 parents who expressed only negative opinions, a significant difference was found for the stress subscale. Parents with solely negative opinions reported significantly higher levels of stress $(M=3.11, S D=6.10$; $t(188)=2.20, p=0.041)$ than those with solely positive opinions $(M=1.83$, $S D=3.75$ ). No significant differences were found for anxiety or depression.

Table 8 Parents' level of depression, anxiety, and stress according to DASS-21 $(n=634)$

\begin{tabular}{llll}
\hline Level & Depression $n(\%)$ & Anxiety $n(\%)$ & Stress $n(\%)$ \\
\hline Normal & $531(83.8)$ & $535(84.4)$ & $533(84.1)$ \\
Mild & $9(21.4)$ & $5(0.8)$ & $10(1.6)$ \\
Moderate & $10(1.6)$ & $5(0.8)$ & $9(1.4)$ \\
Severe & $2(0.3)$ & - & $1(0.2)$ \\
Extreme severe & $1(0.2)$ & $1(0.2)$ & - \\
Missing & $81(12.8)$ & $88(13.9)$ & $81(12.8)$ \\
\hline
\end{tabular}


Using a series of Chi-square tests, no significant associations were found among any of the remaining family circumstance variables (i.e., available time, financial stress, nature of work, number of children, qualification, income, and ethnicity) and parents' positive or negative opinion of mathematics learning at home. In other words, for our sample, family circumstances did not impact the parents' positive or negative experiences of home-learning mathematics. This again suggests that the experience of home-learning mathematics is not only attributable to the parent as some previous research would indicate.

\section{Limitations}

Despite recruiting from a range of different areas of New Zealand, our sample was not representative of the total population and was skewed toward white, middleclass, well-educated, financially secure mothers. This itself is an interesting finding as it indicates a demographic group that may have felt more entitled to weigh in on the topic of the survey. We were surprised by the very low levels of elevated stress evident in our sample, again indicating that the sample was well-resourced and likely more able to weather the situation. The success New Zealand was experiencing in eliminating the virus may have contributed to decreased stress and anxiety by the time of the survey. However, it is important to note that the survey was conducted during the lockdown and at a time when respondents did not know if it would be successful.

Furthermore, the participants tended to have a very high degree of internet and data access. This is likely due to the internet-based nature of the survey; we were constrained from collecting data in other ways due to the lockdown. High uptake of online programs should be considered in light of the fact the respondents, by virtue of their participation, see value in and have access to online modes of communication.

Despite the skewed sample, the large number of respondents generated wideranging responses; this diversity of experience was evident in all demographic groups. We found few differences between groups and evidence of positive, negative, and mixed experiences for every group, which suggests that we need to look beyond the home situation to understand their experiences.

\section{Discussion}

The findings suggest that many underlying issues relating to mathematics homework and home-school partnerships came to the fore during the pandemic. In general, our findings reflect the literature about home learning of mathematics in several ways, suggesting that research about mathematics homework has some salience for the situation of emergency home-learning. For example, mathematics identity of both the parent and child seemed to affect the success of the homelearning experience (Landers, 2013); parents' ability and confidence in mathematics were mentioned (Hyde et al., 2006), the changed mathematics pedagogy 
was clearly evident in parents' comments (Remillard \& Jackson, 2006), and mathematics learning at home was stressful for some (Else-Quest et al., 2008; Lange \& Meaney, 2011). As expected, parents who were negative about the home-learning experience were more stressed; however, we cannot be sure whether it was stress that generated the negativity or the negative experiences of mathematics that created the stress.

While much of the literature related to home learning of mathematics points to the parents as highly influential in the success or not of the interaction, parents certainly described ways in which their situation contributed to difficulties with home-learning mathematics; there were many more responses related to the influence of the school or the teacher. Negativity regarding the school-provided work might be seen as the inverse of deficit views of parents sometimes held by schools (McGee \& Spencer, 2015; Schnee \& Bose, 2010). The large number of mixed responses from parents with more than one child lends support to the notion that the success of mathematics home learning was highly dependent on the material and the support provided by the teacher or school, rather than being about the parents themselves.

Such variety in the quality of support and material provided by different schools and teachers may contribute to poor relationships between school and parents-relationships that the literature shows to be already tenuous (McGee \& Spencer, 2015; Remillard \& Jackson, 2006; Schnee \& Bose, 2010; Wadham et al., 2020). There was certainly some evidence for this in the qualitative data. Not only did a large number of parents mention that lockdown was better for their child's learning of mathematics than school learning, but some explicitly mentioned concern about the quality of their child's school or that they would be looking to change schools after the pandemic. It was clear that some parents were very unhappy with the level or quality of mathematics work provided for their child and the insufficient teaching support. Yet the comments from those parents who had positive experiences and who were agentic in helping their child suggest that there is certainly willingness and ability by parents to be involved in their child's mathematics learning. The fact that parents of older children were less positive about the experience perhaps indicates declining levels of agency or ability for parental input in mathematics home-learning during their educational journey.

A desire to provide material at the right level for their child prompted many parents to turn to online resources. Companies that provide subscription-based programs often advertise that they cater to the individual needs of children, and we saw that many parents found the support they were looking for in these programs. Will the pandemic herald greater use of these programs in schools? Further research would be useful to help decide whether to jump aboard the online learning boat. For example, we may find the programs to be more superficial, less contextual, and less collaborative than the experiences provided by schools. Secondly, the differential access to these programs because of internet data and cost to either schools or family could well highlight a significant equity issue. Inequity was evident in our data set, which was obtained via online survey and skewed to the financially secure; it is safe to assume that equity of access is a significant issue. 


\section{Conclusions: He Waka Eke Noa-Are We All in This Together?}

The phrase he waka eke noa was echoed many times during the pandemic lockdown, and indeed the people of New Zealand were certainly paddling the same boat with regard to following social distancing and other health protocols. Yet our findings indicate that in the context of mathematics education, we were not in it together. Schools independently provided what appears to have been very different mathematics learning experiences for the children of New Zealand, and parents felt very different levels of support from schools and teachers for home learning of mathematics. Because this range of experience occurred despite the government's handling of the crisis, we suggest that the findings are likely applicable worldwide in any context where there is a degree of autonomy for schools. We argue that the messages are, therefore, relevant to an international audience.

At the time of writing, another lockdown in 2021 is imminent; regardless, home learning of mathematics is a part of our typical schooling practices. How then might we paddle forward together, as we look back on these rocky waters and consider a future that will involve some form of home-learning mathematics? The findings of this study suggest that many parents are engaged with their child's mathematics learning and have, particularly at the younger year levels, the resources and the desire to help. However, teacher support is essential for home-learning success. Furthermore, there is evidence to suggest that schools should seek feedback from parents regarding the quality, level, and quantity of the mathematics work provided during home learning; in doing so, they are likely to forge more positive partnerships regarding the mathematics learning of children in the future.

Acknowledgements We would like to thank our research assistant Rachel Woods for all her hard work recruiting participants and engaging in the coding process.

Funding The study was funded by an internal grant from The University of Auckland.

Data availability A copy of the survey used is available on request.

\section{Declarations}

Ethics Approval Ethics approval was granted by the University of Auckland Human Participants Ethics Committee on 22 April (Ref: 024579).

Conflict of Interest The authors declare no competing interests.

\section{References}

Attard, C., \& Holmes, K. (2020). "It gives you that sense of hope": An exploration of technology use to mediate student engagement with mathematics. Heliyon, 6(1), E02945. https://doi.org/10.1016/j. heliyon.2019.e02945

Bano, M., Zowghi, D., Kearney, M., Schuck, S., \& Aubusson, P. (2018). Mobile learning for science and mathematics school education: A systematic review of empirical evidence. Computers \& Education, 121, 30-58. https://doi.org/10.1016/j.compedu.2018.02.006 
Baranovich, D. L., Fong, P.-C., \& Hutagalung, F. (2019). Parental scaffolding in mathematics homework among Malaysian private preschoolers: A case study. International Journal of Science \& Mathematics Education, 17(1), 173-196. https://doi.org/10.1007/s10763-017-9850-2

Bartley, S. R., \& Ingram, N. (2018). Parental modelling of mathematical affect: Self-efficacy and emotional arousal. Mathematics Education Research Journal, 30(3), 277-297. https://doi.org/10.1007/ s13394-017-0233-3

Borba, M. C., Askar, P., Engelbrecht, J., Gadanidis, G., Llinares, S., \& Aguilar, M. S. (2016). Blended learning, e-learning and mobile learning in mathematics education. ZDM Mathematics Education, 48(5), 589-610. https://doi.org/10.1007/s11858-016-0798-4

Braun, V., \& Clarke, V. (2012). Thematic analysis. In H. Cooper, P. M. Camic, D. L. Long, A. T. Panter, D. Rindskopf, \& K. J. Sher (Eds.), APA handbook of research methods in psychology: Vol. 2. Research designs: Quantitative, qualitative, neuropsychological, and biological (pp. 57-71). American Psychological Association. https://doi.org/10.1037/13620-004

Collins, S. (2020, March 18). Coronavirus: Government plan to provide internet and devices to 70,000 children if Covid-19 forces mass school closures. New Zealand Herald. https://www.nzherald.co.nz/nz/ coronavirus-government-plan-to-provide-internet-and-devices-to-70000-children-if-covid-19-forcesmass-school-closures/QHS2HGCVJMG62PB5LGT2PQH7TQ/

Crafter, S. (2012). Parental cultural models and resources for understanding mathematical achievement in culturally diverse school settings. Educational Studies in Mathematics, 81(1), 31-46. https://doi.org/10. 1007/s10649-011-9359-5

Cresswell, J. W. (2014). Research design: Qualitative, quantitative and mixed method approaches (4th ed.). SAGE Publications.

Darragh, L., \& Franke, N. (2021). Online mathematics programs and the figured world of primary school mathematics in the digital era. Mathematics Education Research Journal (online First). https://doi.org/ 10.1007/s13394-021-00384-9

de Abreu, G., \& Cline, T. (2005). Parents' representations of their children's mathematics learning in multiethnic primary schools. British Educational Research Journal, 31(6), 697-722. https://doi.org/10.1080/ 01411920500314869

Drešar, D. A., \& Lipovec, A. (2017). Mathematical experiences and parental involvement of parents who are and who are not mathematicians. Irish Educational Studies, 36(3), 357-374. https://doi.org/10.1080/ 03323315.2017.1333445

Else-Quest, N. M., Hyde, J., \& Hejmadi, A. (2008). Mother and child emotions during mathematics homework. Mathematical Thinking \& Learning, 10(1), 5-35. https://doi.org/10.1080/10986060701818644

Ginsberg, L. (2006). Adult learners go home to their children's math homework: What happens when the parent is unsure of the content? In V. Seabright \& I. Seabright (Eds.), Crossing borders - research, reflection \& practice in adults learning mathematics: Proceedings of the 13th International conference of adults learning mathematics (ALM) (pp. 54-65). Belfast, Northern Ireland: ALM.

Glass, P. (2020). Govt must go harder to save jobs. New Zealand Herald. C7.

Goff, P. (2020). We can get through this by working together. New Zealand Herald. A26.

Henry, J. D., \& Crawford, J. R. (2005). The short-form version of the Depression Anxiety Stress Scales (DASS-21): Construct validity and normative data in a large non-clinical sample. British Journal of Clinical Psychology, 44(2), 227-239. https://doi.org/10.1348/014466505X29657

Hyde, J. S., Else-Quest, N. M., Alibali, M. W., Knuth, E., \& Romberg, T. (2006). Mathematics in the home: Homework practices and mother-child interactions doing mathematics. Journal of Mathematical Behavior, 25(2), 136-152. https://doi.org/10.1016/j.jmathb.2006.02.003

Jay, T., Rose, J., \& Simmons, B. (2018). Why is parental involvement in children's mathematics learning hard? Parental perspectives of their role supporting children's learning. SAGE Open, 8(2). https://doi. org/10.1177/2158244018775466

Knapp, A., Landers, R., Liang, S., \& Jefferson, V. (2017). We all as a family are graduating tonight: A case for mathematical knowledge for parental involvement. Educational Studies in Mathematics, 95(1), 79-95. https://doi.org/10.1007/s10649-016-9741-4

Landers, M. G. (2013). Towards a theory of mathematics homework. Educational Studies in Mathematics, 84(3), 371-391. https://doi.org/10.1007/s10649-013-9487-1

Lange, T., \& Meaney, T. (2011). I actually started to scream: Emotional and mathematical trauma from doing school mathematics homework. Educational Studies in Mathematics, 77(1), 35-51. https://doi.org/10. 1007/s10649-011-9298-1

Lovibond, S. H., \& Lovibond, P. F. (1995). Manual for the Depression Anxiety Stress Scales (2 ${ }^{\text {nd }}$ ed.). Psychological Foundation of Australia.

MacDonald, K. (2020, March 24). It's ok to feel anxious about swift changes. New Zealand Herald, A6. 
McGee, E., \& Spencer, M. B. (2015). Black parents as advocates, motivators, and teachers of mathematics. Journal of Negro Education, 84(3), 473-490. https://www.jstor.org/stable/https://doi.org/10.7709/jnegr oeducation.84.3.0473

McMullen, R., \& de Abreu, G. (2011). Mothers' experiences of the children's school mathematics at home: The impact of being a mother-teacher. Research in Mathematics Education, 13(1), 59-74. https://doi. org/10.1080/14794802.2011.550727

Mendicino, M., Razzaq, L., \& Heffernan, N. T. (2009). A comparison of traditional homework to computersupported homework. Journal for Research in Teacher Education, 41(3), 331-359. https://doi.org/10. 1080/15391523.2009.10782534

Nansen, B., Chakraborty, K., Gibbs, L., Vetere, F., \& MacDougall, C. (2012). "You do the math": Mathletics and the play of online learning. New Media \& Society, 14(7), 1216-1235. https://doi.org/10.1177/14614 44812442926

New Zealand Herald. (2020, March 25). How big, and how long, will global shock be? New Zealand Herald. A19.

Nicholas, K., \& Fletcher, J. (2017). What is happening in the use of ICT mathematics to support young adolescent learners? A New Zealand Experience. Educational Review, 69(4), 474-489. https://doi.org/10. 1080/00131911.2016.1237476

Patall, E. A., Cooper, H., \& Robinson, J. C. (2008). Parent involvement in homework: A research synthesis. Review of Educational Research, 78(4), 1039-1101. https://doi.org/10.3102/0034654308325185

Remillard, J., \& Jackson, K. (2006). Old math, new math: Parents' experiences with standards-based reform. Mathematical Thinking \& Learning, 8(3), 231-259. https://doi.org/10.1207/s15327833mt10803_3

Robin, K., \& Kwak, J. Y. (2018). Comparing types of mathematics apps used in primary school classrooms: An exploratory analysis. Journal of Computers in Education, 5(3), 349-371. https://doi.org/10.1007/ s40692-018-0109-x

Roschelle, J., Feng, M., Murphy, R. F., \& Mason, C. A. (2016). Online mathematics homework increases student achievement. AERA Open, 2(4). https://doi.org/10.1177/2332858416673968

Schnee, E., \& Bose, E. (2010). Parents don't do nothing: Reconceptualizing parental null actions as agency. School Community Journal, 20(2), 91-114. https://www.adi.org/journal/fw10/SchneeBoseFall2010.pdf

Shapira-Lishchinsky, O., \& Zavelevsky, E. (2020). Multiple appearances of parental interactions and math achievement on TIMSS International Assessment. International Journal of Science \& Mathematics Education, 18(1), 145-161. https://doi.org/10.1007/s10763-018-09949-w

Sheldon, S. B., \& Epstein, J. L. (2005). Involvement counts: Family and community partnerships and mathematics achievement. Journal of Educational Research, 98(4), 196-207. https://doi.org/10.3200/JOER. 98.4.196-207

Sheldon, S. B., Epstein, J. L., \& Galindo, C. L. (2010). Not just numbers: Creating a partnership climate to improve math proficiency in schools. Leadership \& Policy in Schools, 9(1), 27-48. https://doi.org/10. 1080/15700760802702548

Statistics New Zealand. (2020). Stats NZ: Population. Retrieved September 10, 2020, from https://www.stats. govt.nz/topics/population

Vazquez, S. R., Ermeling, B. A., \& Ramirez, G. (2020). Parental beliefs on the efficacy of productive struggle and their relation to homework-helping behavior. Journal for Research in Mathematics Education, 51(2), 179-203. https://doi.org/10.5951/jresematheduc-2020-0019

Wadham, B., Darragh, L., \& Ell, F. (2020). Mathematics home-school partnerships in diverse contexts. Mathematics Education Research Journal, Online First. https://doi.org/10.1007/s13394-020-00357-4

Wilder, S. (2017). Parental involvement in mathematics: Giving parents a voice. Education 3-13, 45(1), 104 121. https://doi.org/10.1080/03004279.2015.1058407

Williams, K., Swift, J., Williams, H., \& Van Daal, V. (2017). Raising children's self-efficacy through parental involvement in homework. Educational Research, 59(3), 316-334. :1080/00131881.2017.1344558

Williamson, B., Eynon, R., \& Potter, J. (2020). Pandemic politics, pedagogies and practices: Digital technologies and distance education during the coronavirus emergency. Learning, Media \& Technology, 45(2), 107-114. https://doi.org/10.1080/17439884.2020.1761641

Wright, N., \& Peters, M. (2017). Sell, sell, sell or learn, learn, learn? The EdTech market in New Zealand's education system - privatisation by stealth? Open Review of Educational Research, 4(1), 164176. https://doi.org/10.1080/23265507.2017.1365623 